\title{
Grand challenges in advanced fossil fuel technologies
}

\author{
Jennifer Wilcox * \\ Energy Resources Engineering, Stanford University, Stanford, CA, USA \\ ${ }^{*}$ Correspondence: jen.wilcox@stanford.edu \\ Edited by: \\ Adam Robert Brandt, Stanford University, USA \\ Reviewed by: \\ Niall Mac Dowell, Imperial College, UK
}

Keywords: fossil fuels, fossil-based energy resources, increased energy efficiency, water conservation, bioenergy

\section{INTRODUCTION}

Turn your ignition key and fuel ignites, pushing pistons, powering your automobile, and allowing you freedom and mobility. Simple! We drive to work; we drive for vacations; we drive just to drive. Transportation is just one of the many examples of society's dependence on fossil fuels. Today, the burning of fossil fuels, including coal, oil, and gas meets more than $85 \%$ of the world's energy needs. Figure 1A shows the distribution of the energy resources that meet the global consumption. Although renewable energy sources accounted for a record high of $2.7 \%$ of consumption in 2013, fossil-based energy resources continue to dominate the portfolio with oil, coal, and natural gas representing 33,30 , and $24 \%$ of global energy consumption, respectively (British Petroleum, 2013). Given our history and current reliance, it appears that fossil fuels are here to stay as long as they remain available. Technological advances in the recovery and transformation of fossil fuels to energy will be required in order to ensure that our usage of these resources will be environmentally sustainable with minimal impact to our environment and our quality of life.

Fossil fuels are limited in the Earth and yet we have been igniting them $24 \mathrm{~h} /$ day for over a century. As a result, we live in a world that is warming faster than at any other time in human history due to the increase of carbon dioxide $\left(\mathrm{CO}_{2}\right)$ in the atmosphere. Science tells us that there will be winners and losers in a rapidly warming world; however, there will be many more losers than winners. Animal species will face extinction. Ecosystems will collapse. Coastal cities will flood. Droughts and floods, stronger storms, wild fires, and other disasters will become more abundant. And while the Western world is wealthy and resilient enough to buffer against more frequent climate extremes, the world's poorest, well over a billion men, women, and children, are not. As the population is expected to increase from seven billion to nine billion, the conservation of water, land, and materials will be essential to maintain quality of life. Water is a crucial component to energy production. The process of extracting energy from fossil fuels must be optimized in order to limit water usage while minimizing $\mathrm{CO}_{2}$ and other harmful emissions. Building clean-burning power plants with increased efficiency and low water requirements are objectives that will need to be met if the globe is able to withstand this forecasted population increase.

In particular, grand challenges that will require our attention in the coming decades include: an increase in efficiency of the way in which energy is extracted from fossil fuels, the conservation of water in energy production, the sustainable recovery of fossil fuels, the flexibility of fuel generation, and an increased reliance on bioenergy.

\section{INCREASED EFFICIENCY}

Increasing the efficiency of a power plant leads to reduced emissions and a decrease in water and materials required for operation. Advancing boiler technology is a means of significantly increasing the efficiency of a power plant. For instance, most of the power plants in the US are subcritical, with efficiencies averaging around $35 \%$ (HHV) (Wilcox, 2012). However, the newer power plants that are currently being built in China are based heavily on ultrasupercritical boiler technology and have efficiencies averaging close to 50\% (HHV). In fact, China has become a global leader in advancing coal-fired power generation, with $>1 \mathrm{GW}$ of ultra-supercritical units installed (Qili, 2013). The development of thermally resistant alloys has been decisive in the advancement of this technology. Natural gas combined cycle and integrated gasification combined cycle (IGCC) technologies are also improvements to the conventional subcritical coal-fired power plants, with efficiencies averaging just above 50 and 40\%, respectively (Wilcox, 2012). As advances in carbon capture are being made, efficiency gains will become increasingly important given that the separation process requires energy, often in the form of steam, thereby significantly reducing a given plant's efficiency. If $\mathrm{CO}_{2}$ is to be captured on the gigatons scale, as is required for significant climate mitigation, hybrid approaches may be needed in order to maintain reasonable efficiencies of power plants. For instance, the use of noncarbonized energy resources such as wind and solar may be integrated into the plant design for providing the required energy for $\mathrm{CO}_{2}$ capture or the operation of other pollutant scrubbing processes.

\section{WATER CONSERVATION}

Water is an essential component to energy production. Significant amounts of water are needed for coal mining, oil recovery, gasoline refining, and the generation and distribution of electricity from coal and natural gas resources. Projections from BP indicate a $36 \%$ increase in global energy consumption by 2030; however, the Water Resources Group anticipate that there will be a $40 \%$ shortage of freshwater to meet global demand over this same time frame (Water Resources Group, 2009; British Petroleum, 2013). In particular, in the case of coal, water is used to extract, wash, and process it. In addition, coal-fired power plants require water for steam production and cooling. Once-through cooling systems have the most water-intensive needs, using between 20,000 and 50,000 

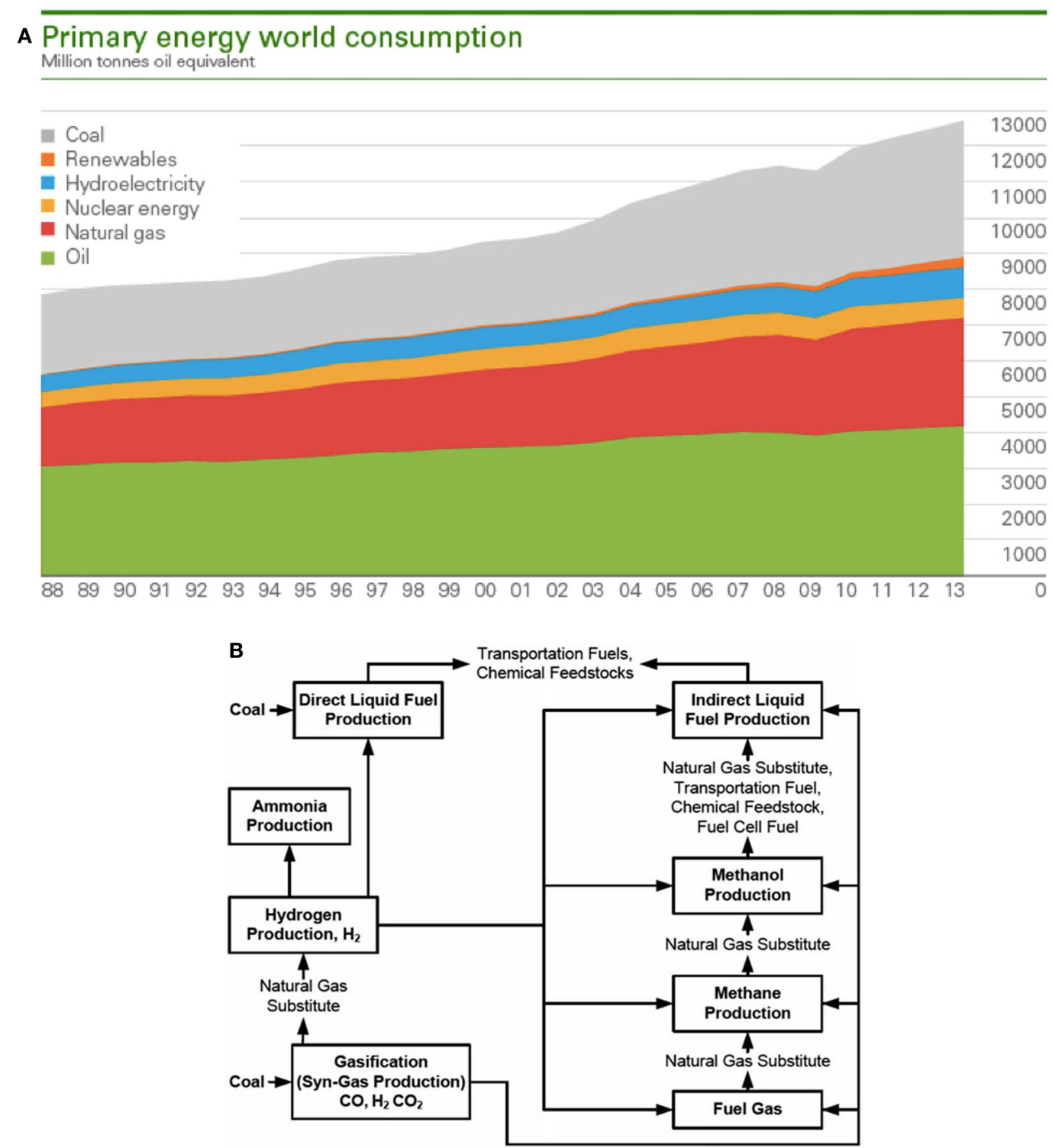

FIGURE 1 | (A) Primary energy world consumption (million tons of oil equivalent) is shown. Fossil fuels represent a total of $87 \%$ of global energy consumption and are steadily rising (British Petroleum, 2013). (B) Schematic of fuel and chemical products produced from $\mathrm{CO}$ and $\mathrm{H}_{2}$ via the Fischer-Tropsch process, exhibiting the flexibility in coal Milcox, 2012).

gallons per megawatt hour of electricity (Luo et al., 2014). Currently, just over 50\% of the coal-fired power plants in the US use once-through cooling with the majority of the remaining using recirculating. In addition, approximately $30 \%$ of natural gas-fired power plants in the US depend upon once-through cooling (US Energy Information Agency, 2012). In general, water consumption for energy production in the US is expected to increase by nearly $70 \%$ in 2030 , whereas water consumption for biofuel production is expected to increase by almost $250 \%$ (Elcock and Future, 2010). Strategies that address water reduction methods for the use of fossil fuels in energy generation will be required for the water energy nexus challenge.

\section{SUSTAINABLE RECOVERY}

As methods such as horizontal drilling and fracturing with $\mathrm{CO}_{2}$ are advanced for the recovery of unconventional oil, the peak in oil production continues to shift. It is important that advanced methods used for the recovery of unconventional resources are carried out in a way that limits negative environmental impacts and minimizes precious resources such as freshwater. In addition, natural gas recovery from low permeability shale rock will require similar approaches and will pose similar threats to the environment if not considered carefully. In the recovery and distribution of natural gas, understanding the extent of methane leakage is also a challenge that will require attention (Brandt et al., 2014). The development of techniques for monitoring and measuring methane in the atmosphere 
will lead to improved understanding and quantification of its role in global warming. Methods for the environmentally sustainable and safe recovery of oil, natural gas, and coal should be advanced such that they pose as minimal a threat as possible to the environment and to local communities potentially influenced.

\section{FUEL FLEXIBILITY}

Through gasification of coal (IGCC) and natural gas, oxygen is supplied in a controlled fashion that allows the process to suppress the formation of water and instead produces primarily $\mathrm{CO}$ and hydrogen gas, also known as synthesis gas (CO and $\mathrm{H}_{2}$ ). The concentration of $\mathrm{CO}_{2}$ generated from this process is substantially greater than in coal combustion, which makes its separation from the fuel gas mixture easier, thereby requiring less energy. For electricity generation, the synthesis gas (largely hydrogen) is burned directly and then passed through a gas turbine for electricity generation. The heat recovered from this process is used to generate steam, which is passed through a steam turbine for additional electricity generation, resulting in a combined cycle. Rather than directly combusting the synthesis gas in an IGCC process, the syngas may also be converted to fuel and/or chemicals via Fischer-Tropsch (FT) synthesis as shown in Figure 1B. The largest scale FT operation based on a coal-to-liquid (CTL) conversion process is operated by Sasol in South Africa, which is high in coal reserves and low in petroleum (Leckel, 2009). In regions such as South Africa, Australia, China, and India, this technology serves as a means to create fuel or chemicals from coal, given that this is the dominant energy resource available in these regions. An important parameter for controlling the FT conversion and selectivity is the hydrogen-carbon ratio (H/C). The required H/C ratio for commercial production of hydrocarbon fuels, i.e., diesel and gasoline, is approximately 2 on a molar basis, while the ratio ranges from 1.3 to 1.9 for petroleum crude oil and 0.8 for typical bituminous coals (Williams and Larson, 2003). A critical challenge for FT conversion is increasing the $\mathrm{H} / \mathrm{C}$ ratio or the $\mathrm{H}_{2} / \mathrm{CO}$ ratio. The future of CTL processes may be limited due to: (1) its competition with existing "alternative liquid fuels," such as biofuels, as well as (2) its inevitable result of net $\mathrm{CO}_{2}$ emissions, since the $\mathrm{H}: \mathrm{C}$ ratio is higher in liquids than in coal.

\section{ROLE OF BIOENERGY}

Bioenergy is the production of energy from burning biomass or co-firing biomass with coal or natural gas. Since plants uptake $\mathrm{CO}_{2}$ from the atmosphere via photosynthesis with sufficient sunlight, water, and nutrients (e.g., bioavailable nitrogen and phosphorus or fertilizers) as additional inputs, the concept is that bioenergy results in a net reduction of $\mathrm{CO}_{2} \mathrm{com}-$ pared to conventional fossil fuel burning. Biomass also can be used to produce liquid fuels, such as ethanol or methanol, or gas fuels, such as hydrogen. Both the availability of land for biomass cultivation and the need to transport bulky biomass to processing facilities severely limits the feasible use of bioenergy. In addition, advancing bioenergy to a reasonable scale requires extensive land area. More specifically, $100 \mathrm{EJ} /$ year may require up to 500 million hectares of land, assuming an average biomass yield of 10 tons of dry biomass/hectare annually. By comparison, the Food and Agriculture Organization (FAO) estimates that in 2008, global arable land amounted to approximately 1,400 million hectares, out of an approximate total of 4,900 million hectares of land used for agriculture (FAO, 2010). Global food demands are projected to nearly double over the next 50 years (Tilman et al., 2001), which in the absence of dramatic yield increases or diet changes, will put energy crops in direct competition with food crops for arable land. For bioenergy to reach its potential, advances will need to be made in terms of burner/boiler design for cofiring biomass with coal and/or natural gas for both combustion and gasification applications.

\section{FINAL THOUGHTS}

Will we adapt to a rapidly warming world or will we make the individual changes that slow or reverse the negative impacts? Probably, a bit of both. Our behavior and the choices that we make will determine the legacy that we leave for future generations. Likely, there will be no one solution, but rather a portfolio of solutions depending upon geography and available energy resources. If we are to slow or decrease the negative impacts of climate change, advancing fossil fuel technologies will be paramount in moving forward as our continued reliance on these energy resources is only projected to increase in coming years.

\section{REFERENCES}

Brandt, A. R., Heath, G. A., Kort, E. A., O’Sullivan, F., Petron, G., Jordaan, S. M., et al. (2014). Methane leaks from North American natural gas systems. Science 343, 733-735. doi:10.1126/science. 1247045 British Petroleum. (2013). BP Energy Outlook 2030, Statistical Review. London: British Petroleum.

Elcock, D., and Future, U. S. (2010). Water consumption: the role of energy production. J. Am. Water Resour. Assoc. 46, 447-460. doi:10.1111/j. 1752-1688.2009.00413.x

FAO. (2010). FAO Statistical Yearbook 2010. Rome: Food and Agriculture Organization of the United Nations.

Leckel, D. (2009). Diesel production from FischerTropsch: the past, the present, and new concepts. Energy Fuels 23, 2342-2358. doi:10.1021/ef900064c

Luo, T., Otto, B., Shiao, T., and Maddocks, A. (2014). Identifying the global coal industry's water risks. Cornerstone 2, 26-31.

Qili, H. (2013). The development strategy for coalfired power generation in China. Cornerstone 1, 19-23.

Tilman, D., Fargione, J., Wolff, B., D’Antonio, C., Dobson, A., Howarth, R., et al. (2001). Forecasting agriculturally driven global environmental change. Science 292, 281-284. doi:10.1126/science.1057544

US Energy Information Agency. (2012). "Form EIA860," in Annual Electric Generator Report. Washington, DC.

Water Resources Group. (2009). Charting our Water Future. McKinsey and Company.

Wilcox, J. (2012). Carbon Capture. New York: Springer. Williams, R. H., and Larson, E. D. (2003). A comparison of direct and indirect liquefaction technologies for making fluid fuels from coal. Energy Sustain. Dev. 7, 103-129. doi:10.1016/S0973-0826(08) 60382-8

Conflict of Interest Statement: The Associate Editor Adam Robert Brandt declares that, despite being affiliated to the same institution as author Jennifer Wilcox, and despite having collaborated on a manuscript in the past 2 years, the review process was handled objectively and no conflict of interest exists. The author declares that the research was conducted in the absence of any commercial or financial relationships that could be construed as a potential conflict of interest.

Received: 02 October 2014; accepted: 14 October 2014; published online: 14 November 2014.

Citation: Wilcox J (2014) Grand challenges in advanced fossil fuel technologies. Front. Energy Res. 2:47. doi: 10.3389/fenrg.2014.00047

This article was submitted to Advanced Fossil Fuel Technologies, a section of the journal Frontiers in Energy Research.

Copyright (c) 2014 Wilcox. This is an open-access article distributed under the terms of the Creative Commons Attribution License (CC BY). The use, distribution or reproduction in other forums is permitted, provided the original author(s) or licensor are credited and that the original publication in this journal is cited, in accordance with accepted academic practice. No use, distribution or reproduction is permitted which does not comply with these terms. 